\title{
COMPARING BROAD-BAND AND RED EDGE-BASED SPECTRAL VEGETATION INDICES TO ESTIMATE NITROGEN CONCENTRATION OF CROPS USING CASI DATA
}

\author{
Yanjie Wang ${ }^{\mathrm{a}}$, Qinhong Liao ${ }^{\mathrm{b}}$, Guijun Yang ${ }^{\mathrm{b}, *}$, Haikuan Feng ${ }^{\mathrm{b}}$, Xiaodong Yang ${ }^{\mathrm{b}}$, Jibo Yue ${ }^{\mathrm{a}}$ \\ ${ }^{a}$ School of Surveying and Land Information Engineering, Henan Polytechnic University, Jiaozuo 454003, China - \\ yanjie6wang@163.com \\ ${ }^{\mathrm{b}}$ Beijing Research Center for Information Technology in Agriculture, Beijing Academy of Agriculture and Forestry Sciences, \\ Beijing, 100097, China - guijun.yang@163.com
}

Commission VII, WG VII/3

KEY WORDS: LNC, SVIs, NDVI, broad-band, red edge-based, CASI

\begin{abstract}
:
In recent decades, many spectral vegetation indices (SVIs) have been proposed to estimate the leaf nitrogen concentration (LNC) of crops. However, most of these indices were based on the field hyperspectral reflectance. To test whether they can be used in aerial remote platform effectively, in this work a comparison of the sensitivity between several broad-band and red edge-based SVIs to LNC is investigated over different crop types. By using data from experimental LNC values over 4 different crop types and image data acquired using the Compact Airborne Spectrographic Imager (CASI) sensor, the extensive dataset allowed us to evaluate broadband and red edge-based SVIs. The result indicated that NDVI performed the best among the selected SVIs while red edge-based SVIs didn't show the potential for estimating the LNC based on the CASI data due to the spectral resolution. In order to search for the optimal SVIs, the band combination algorithm has been used in this work. The best linear correlation against the experimental LNC dataset was obtained by combining the $626.20 \mathrm{~nm}$ and $569.00 \mathrm{~nm}$ wavebands. These wavelengths correspond to the maximal chlorophyll absorption and reflection position region, respectively, and are known to be sensitive to the physiological status of the plant. Then this linear relationship was applied to the CASI image for generating an LNC map, which can guide farmers in the accurate application of their $\mathrm{N}$ fertilization strategies.
\end{abstract}

\section{INTRODUCTION}

\subsection{General Instructions}

The Nitrogen concentration is one of the most important $\mathrm{N}$ nutrient diagnosis indicators of plants, which the plant growth, yield, and quality have a close relation with; it is often positively associated with leaf chlorophyll content and photosynthetic capacity (Stroppiana et al., 2009; Li et al., 2014b). However, excessive application of nitrogen fertilizer will induce the nitrate nitrogen $\left(\mathrm{NO}_{3}-\mathrm{N}\right)$ losses in crop production, which is considered to be one of the major agricultural non-point pollutions (Inoue et al., 2012). Hence, timely and effectively detecting the nitrogen concentration of crops on a regional scale is important not only to obtain the growth status of crops but also to gain an overview of the nitrogen spatial distribution, which can guide farmers to implement the precision fertilization technology in the field. In recent decades, remote sensing has been recognized as a reliable method for estimating the nitrogen concentration due to it is functionally linked to the canopy spectral reflectance (Feng et al., 2014). There have two widespread approaches to retrieve nitrogen concentration from reflectance measurements. One of them is a physically-based method, which uses models that simulate reflectance spectra from leaf biochemical parameters and vice versa (Darvishzadeh et al., 2012). However, this approach generally involves the "ill-posed" inverse problem for lack of sufficient prior knowledge. An alternative approach is the empirical retrieval methods, which typically consist of relating the nitrogen concentration against spectral vegetation indices (SVIs) through linear or nonlinear algorithmic techniques (Kanke et al., 2012). The advantage of vegetation indices is that they allow obtaining the information between spectral reflectance and nitrogen concentration in a fast and easy way and the underlying mechanisms are well-understood. The characteristic absorption wavebands of nitrogen $(1510 \mathrm{~nm}$, $1730 \mathrm{~nm}, 1940 \mathrm{~nm}$, etc.) are mainly in the short-wave infrared region, which can be well used to design the SVIs of nitrogen, whereas there have two strong water absorption wavebands $(1450 \mathrm{~nm}, 1940 \mathrm{~nm})$ also plays a significant role in this spectral range, that masked the sensitive wavebands of nitrogen. So, several researchers designed the SVIs by using the red edge wavebands based on the good correlation between nitrogen and chlorophyll (Chen et al., 2010; Clevers, Jan G. P. W. and Kooistra, 2012). Li et al. (Li et al., 2014a) evaluated the rededge based spectral indices for estimating plant $\mathrm{N}$ concentration and uptake of summer maize, they found that the red edgebased canopy chlorophyll concentration (CCCI) had good performance. Although the red edge-based SVIs showed promising potential for estimating the nitrogen concentration in many studies, but they are mostly constructed by using field hyperspectral reflectance. When the red edge-based SVIs are applied to an aerial platform, many factors such as the scale and spectral resolution should be considered. So far, little literature 
has been reported on evaluating the potential of using red edgebased spectral vegetation indices for estimating nitrogen concentration based on the aerial remote sensing data, as compared with commonly used broad-band SVIs such as NDVI, RVI, GNDVI and CVI. Therefore, the objectives of the present study were (i) to evaluate broad-band and red edge-based SVIs for estimating crop nitrogen concentration, (ii) to infer the most powerful and robust two-band vegetation indices from CASI data for estimating nitrogen concentration, and (iii) to map the spatial distribution of nitrogen concentration in the study area.

\section{TITLE AND ABSTRACT BLOCK}

\subsection{Site description}

The aerial experiment was carried out on July 7, 2012 in the Heihe River basin ( $38^{\circ} 54^{\prime} \mathrm{N}, 100^{\circ} 24^{\prime}$ E), Gansu province, northwest China (Fig 1). The climate in this area is a humid continental monsoon, with very cold winters and warm summers. The annual average temperature, precipitation, and solar amounts are $2.8-7.6{ }^{\circ} \mathrm{C}, 200-300 \mathrm{~mm}$ and 3000-4000h, respectively. These climatic characteristics are suitable for many field crops (e.g. corn, wheat, rice and soybeans), which have only one harvest per year. As the most widely planted crop in this area, it has become one of the most important commodity grain bases in China.

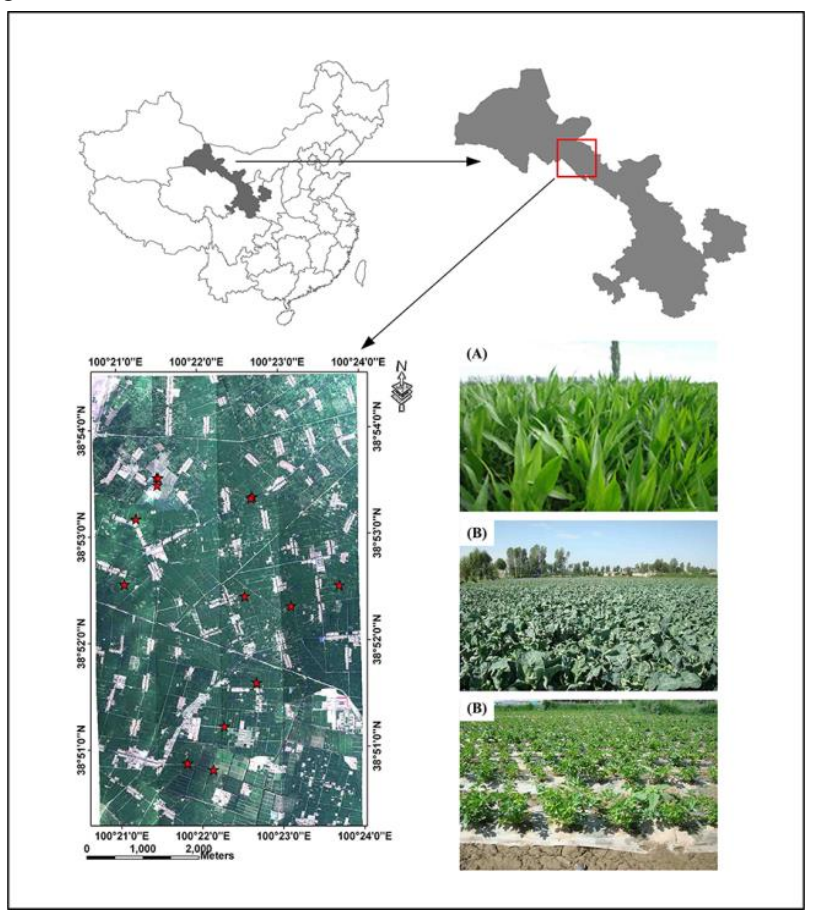

Figure 1. CASI image of the crops acquired on July 7, 2012

\subsection{Acquisition of field and CASI data}

To establish a meaningful relationship between nitrogen concentration and CASI data, ground measurements should be collected at the same time of image acquisition. Based on this, the ground-based measurements were taken on July 7, 2012, meanwhile, the CASI hyperspectral sensor was flown over the experimental sites at a flight altitude of $2000 \mathrm{~m}$. The acquired image data have $1 \mathrm{~m}$ spatial resolution and forty-eight spectral bands with a bandwidth of $14 \mathrm{~nm}$. In the field, fifteen plots of maize and vegetables were sampled and each plot center locations were recorded with a real-time differential global positioning system. For the acquired CASI data, the uncalibrated images were converted into radiance by using calibration coefficients calculated from the field hyperspectral reflectance. After that, the atmospheric and geometric correction were carried out by FLAASH module of ENVI software. To obtain a representative plant sample, the plants were destructively sampled by randomly cutting 2-3 leaves in the upper layers after the CASI hyperspectral sensor flied. All green leaves were separated from stems and oven-dried at $70^{\circ} \mathrm{C}$ and weighed. Dried leaf samples were ground and passed through a $1 \mathrm{~mm}$ screen, and stored in plastic bags for subsequent analysis. The LNC (g per $100 \mathrm{~g}$ dry weight) was measured by using the Kjeldahl-N method.

\subsection{Calculation of vegetation indices}

To identify the best-performing algorithms and indices, we developed, tested and compared three types of algorithms and their corresponding indices, based on the relationship between the nitrogen concentration and spectral reflectance (Table 1). First, the commonly used indices are broad-band SVIs (e.g. NDVI, RVI, GNDVI, CVI), most of them were initially developed for the study of LAI. Since they were originated from broad-band sensors, which forms still the majority of the Earth observing satellites. Second, various alternatives to the conventional broad-band vegetation indices have been proposed with the advent of hyperspectral technique. So, we tested a wide range of red edge-based vegetation indices such as REP, MTCI, CIred edge, etc. to acquire the most useful information on crop growth and nitrogen status. Third, in an attempt to further optimize the sensitivity of these vegetation indices, the NDSI and RSI were used to evaluate all two-band combinations in the range of $425.70-1055.50 \mathrm{~nm}$ that lead to optimizing linear correlation with nitrogen concentration using CASI data, the evaluation was done by calculating the coefficient of determination $\left(\mathrm{R}^{2}\right)$. By this approach, it was demonstrated that the better results were retained in only a few selected bands while the rest becoming redundant. Specifically, $\mathrm{Li}$ et al. (Li et al., 2014b) have explored that the band combination between 600 and $800 \mathrm{~nm}$ can improve the estimation of summer maize nitrogen status. However, this investigation was only done by field hyperspectral reflectance, whether it can be applied to the aerial remote sensing data should be further verified.

\begin{tabular}{ccc}
\hline Vegetation index & Formula & Reference \\
\hline $\begin{array}{c}\text { Broad-band vegetation } \\
\text { indexes }\end{array}$ & & \\
$\begin{array}{c}\text { Normalized difference } \\
\text { vegetation index (NDVI) }\end{array}$ & $\frac{R_{\text {nir }}-R_{\text {red }}}{R_{\text {nir }}+R_{\text {red }}}$ & (Tucker, 1979) \\
\hline
\end{tabular}




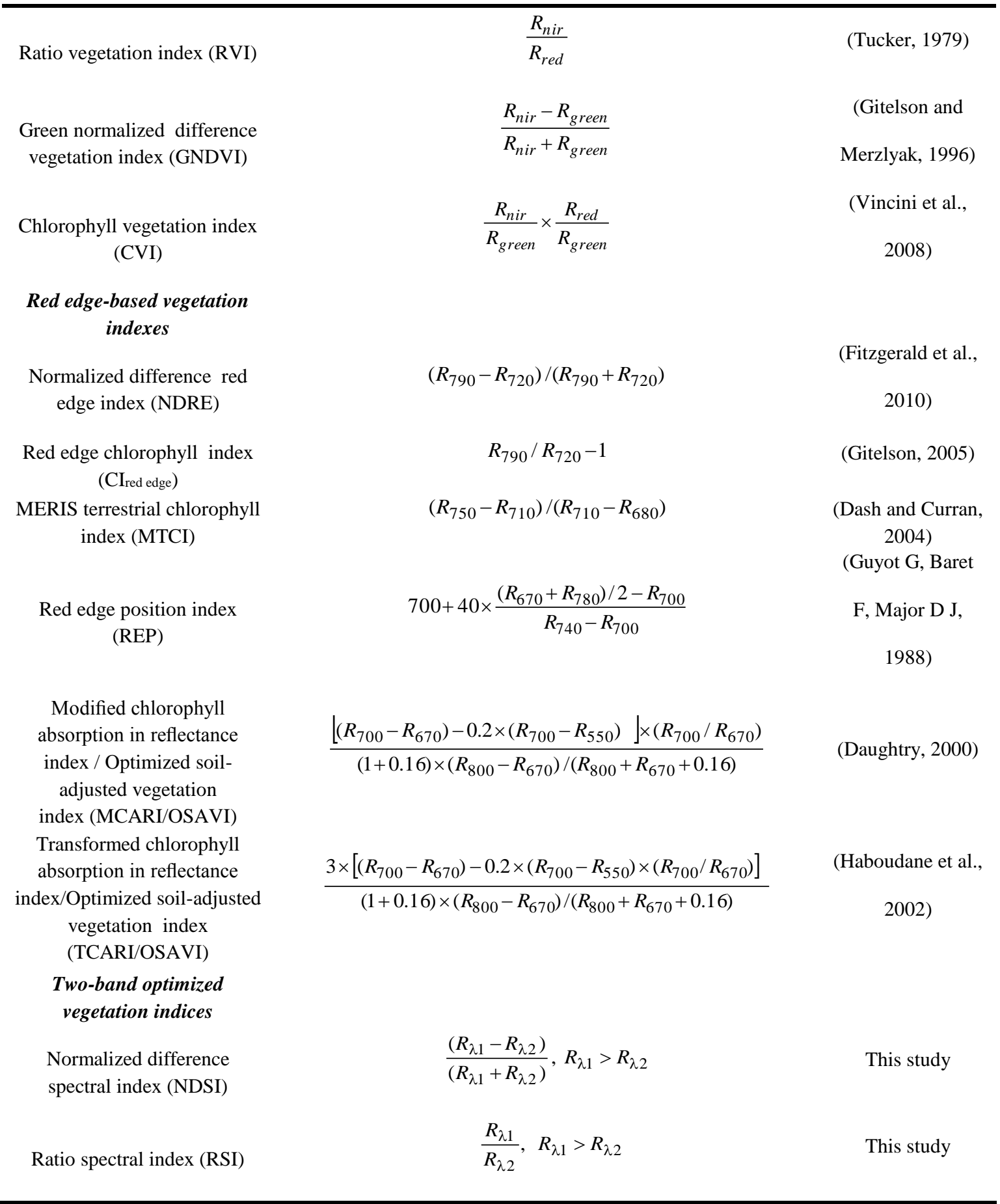

Table 1. Vegetation indices used in this study, where $R_{\lambda}$ is the reflectance at wavelength $\lambda(\mathrm{nm})$

\section{RESULTS}

\subsection{Evaluating vegetation indices to estimate the nitrogen concentration}

The Heihe River basin field dataset, along with the ensemble of CASI images, was used to develop a simple spectral method applicable for remote sensing estimation of nitrogen concentration over a complete set of different crops. Results indicated that the most widely used SVIs, NDVI and RVI, proposed by Tucker (Tucker, 1979) have shown the higher $\mathrm{R}^{2}$ values $(0.50$ and 0.51$)$. Because NDVI saturates easily at moderate to high canopy coverage conditions, green waveband substituted the red region (strong pigment absorption waveband) and incorporated into the normalized vegetation index, however, the GNDVI-based model didn't perform significantly better than the aforementioned vegetation indices (Fig 2). Several researches pointed out that the relationship between LNC and chlorophyll is linear (Clevers, Jan G. P. W. and Kooistra, 2012), so vegetation indices best for estimating leaf chlorophyll may be the best indicators for estimating leaf and plant nitrogen concentration. Chlorophyll vegetation index (CVI) (Vincini et al., 2008), a broad-band vegetation index that is sensitive to leaf chlorophyll, was investigated in this study. But there has no correlation between the CVI and nitrogen concentration $\left(\mathrm{R}^{2}=0.07\right)$, which is not a good candidate. Thus, in order to compare the estimation accuracy 
with the narrow-band SVIs, six red-edge vegetation indices developed by using hyperspectral reflectance were tested. The result showed that NDRE, REP and TCARI/OSAVI which
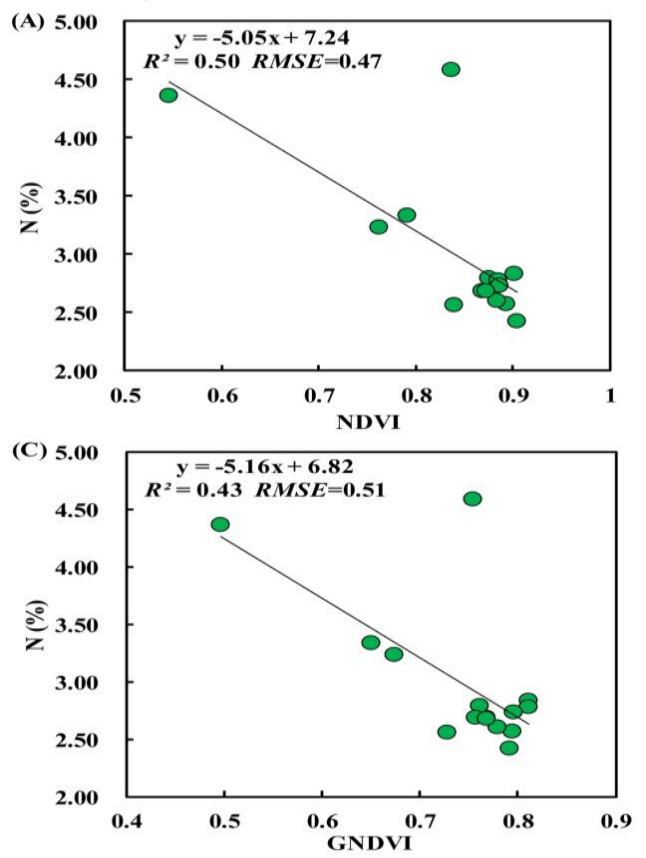

performed well in estimating crop nitrogen concentration (Fig 3) while lower $\mathrm{R}^{2}$ values were generated by the other red-edge vegetation indices (CIred edge, MTCI and MCARI/OSAVI).
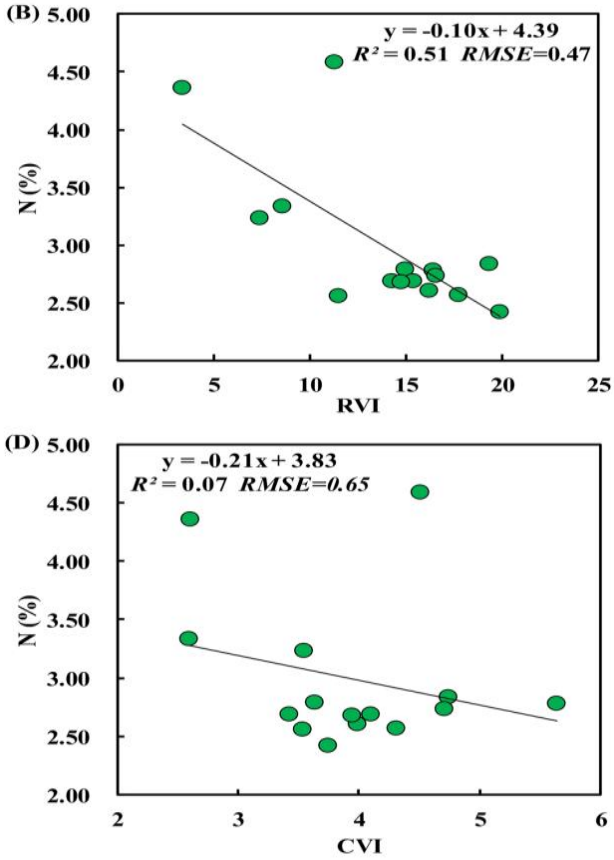

Figure 2. Relationships between broad-band SVIs and nitrogen concentration
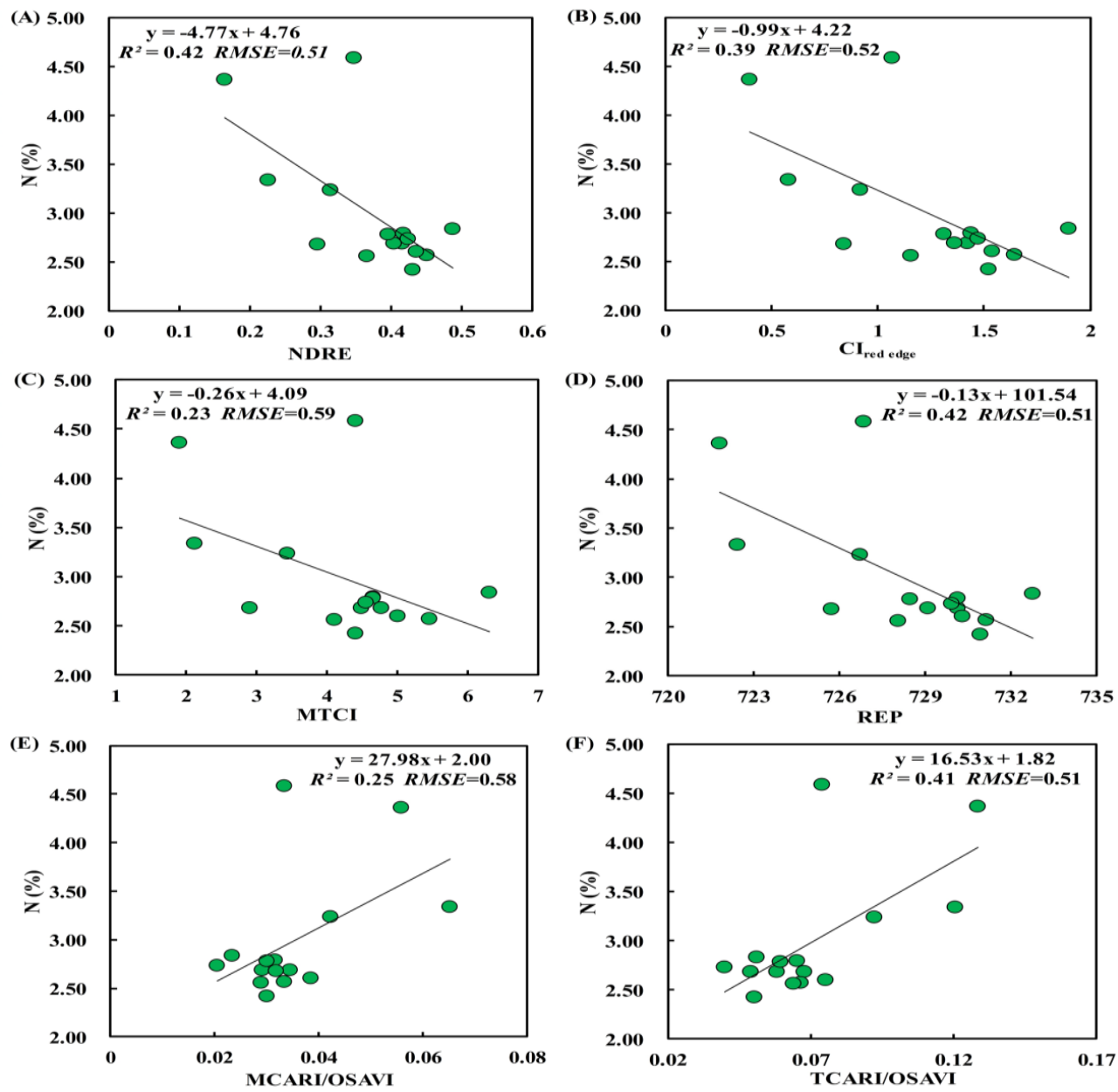

Figure 3. Relationships between broad-band SVIs and nitrogen concentration 


\subsection{Evaluation of optimized spectral vegetation indices}

To evaluate the stability of spectral indices in estimating plant nitrogen concentration, we established the relationships between NDSI, RSI and LNC by all possible combinations of two wavebands. Each of these indices was subsequently correlated with $\mathrm{LNC}$ using linear regression and $\mathrm{R}^{2}$ was calculated. The resulting correlation matrices shown in Fig 4, enables us to inspect variation in the $\mathrm{R}^{2}$ coefficient over all the two-band combinations. The figure is marked by an optimized region shown in red with strong correlations and a maximum $\mathrm{R}^{2}$ of 0.65 and 0.64 were obtained by the two-band combination of $\mathrm{i}=626.20$ and $\mathrm{j}=569.00 \mathrm{~nm}$. Compared with broad-band and red edge-based SVIs, optimized normalizationbased NDSI has significantly increase the predictive power of LNC.
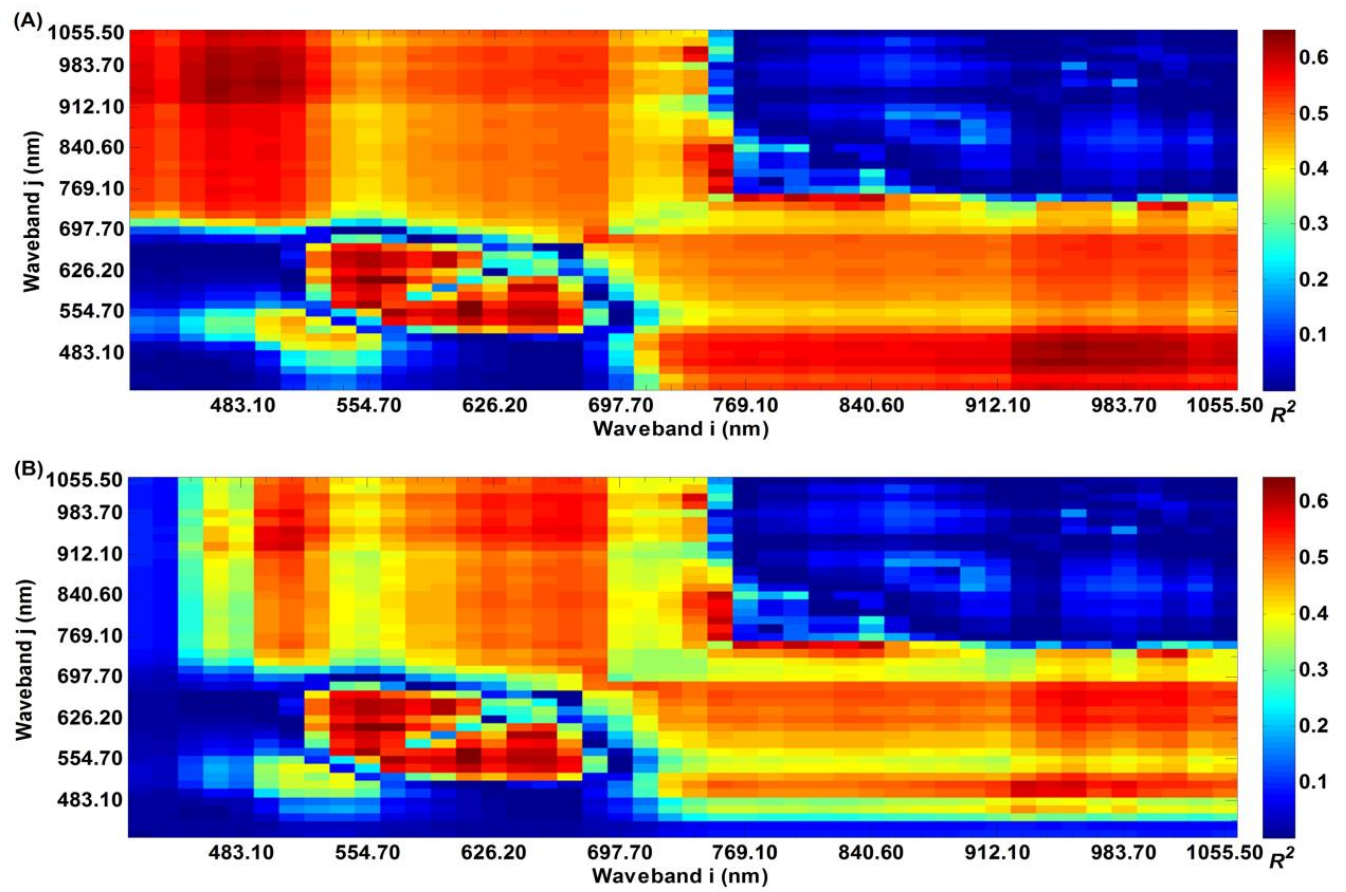

Figure 4. Contour diagrams of the coefficient of determination $\left(R^{2}\right)$ between $\operatorname{NDSI}_{(i, j)}, \operatorname{RSI}_{(i, j)}$ and nitrogen content (The letters A, B represent NDSI and RSI, respectively.)

Figures Fig 5 shows the resulting relationship between its values and the measured LNC values in a scatterplot. A linear relationship can be fitted through the data points according to the following regression equation:

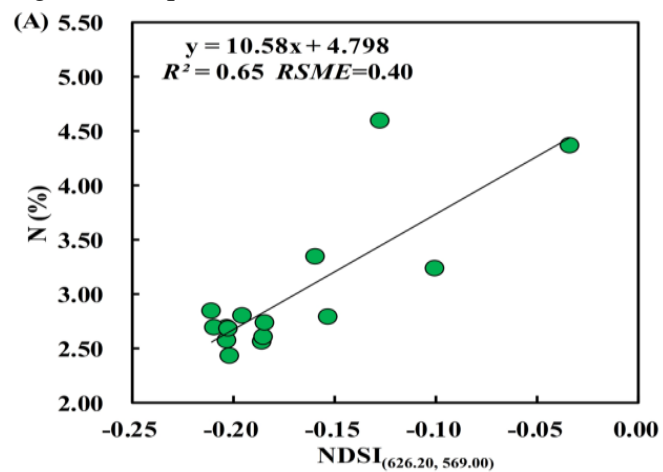

$\mathrm{LNC}=10.58 \times \operatorname{NDSI}_{(626.20,569.00)}+4.80$

Where $\operatorname{NDSI}_{(626.20,569.00)}$ has been calculated using the 626.20 and $569.00 \mathrm{~nm}$ bands.

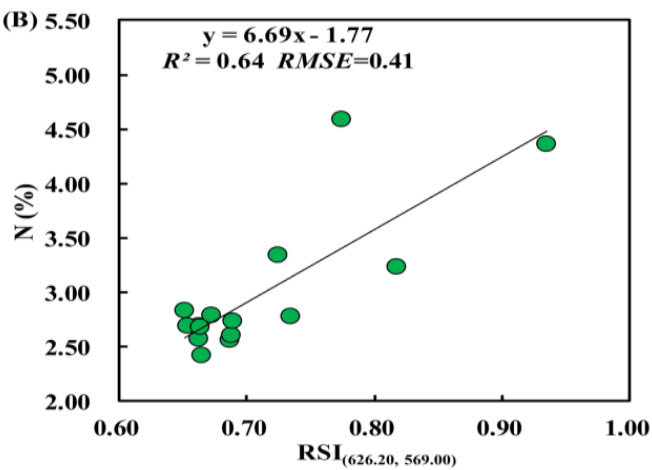

Figure 5. Relationships between NDSI, RSI and LNC

This regression equation yielded a strong linear correlation with field LNC measurements. So, the next step consists of applying this equation to the CASI image, which leads to an LNC map over the study area. Given the final map in Fig 6, different LNC spatial distribution can be distinguished based on the image. The green and red tones represent LNC distributions ranged from $0.79 \%$ to $5.76 \%$, which shows that the proposed NDSI performs adequately for obtaining large areas LNC maps over an entire crop from space-based imagery. 


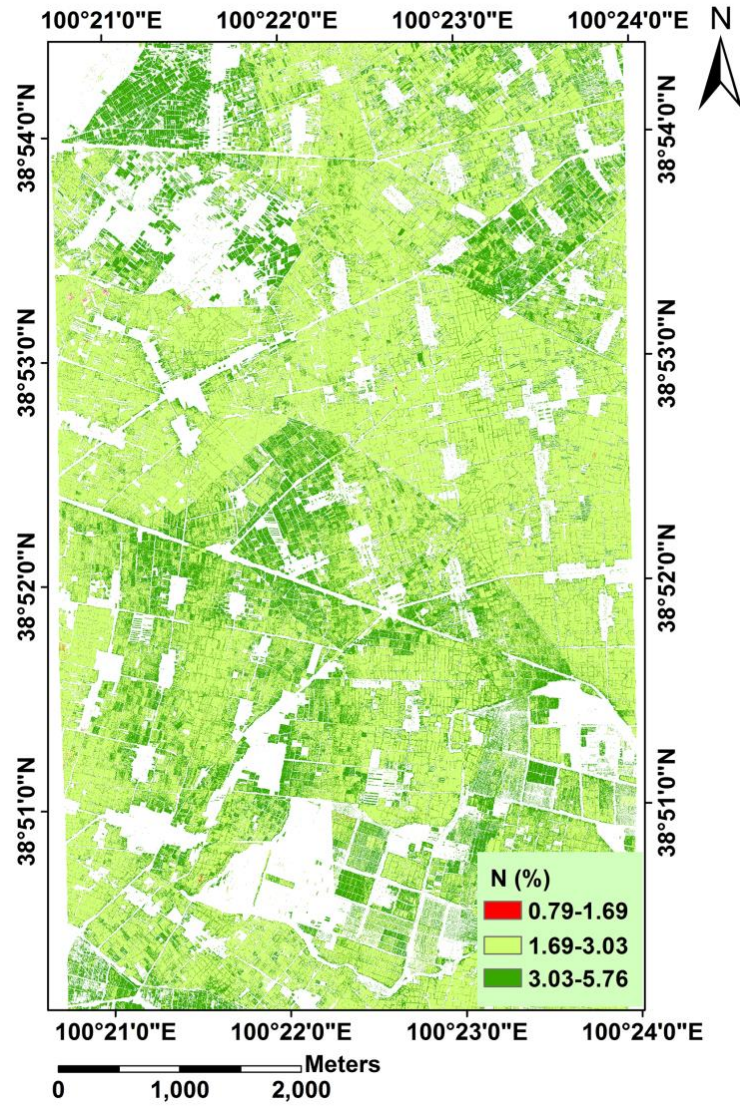

Figure 6. Maps showing the spatial variation of nitrogen concentration using $\operatorname{NDSI}_{(626.20,569.00)}$ based on the CASI data

\section{DISCUSSION}

Plant nitrogen concentration and uptake are important crop nitrogen status indicators, which can be used to guide farmers for nitrogen management. Remote estimation of the LNC of crops have been comprehensively discussed by many studies (Chen et al., 2010; Clevers, Jan G. P. W. and Kooistra, 2012; Kanke et al., 2012). Most of the studies addressed in these papers are based on the vegetation indices developed with field hyperspectral reflectance. The results found in these studies showed that the spectral parameters used were closely related to the LNC. In contrast, our experiment was conducted by the aerial sensor, which obtained the high spatial resolution imagery allowing identification of within-field variations in LNC. Since more nitrogen supply can increase chlorophyll, which absorbs more light and decreases reflectance of visible wavebands, meanwhile, excessive nitrogen fertilizer can also increase plant biomass and LAI, resulting in more scattering back of incident solar radiation in the NIR region by the plant canopy (Heege et al., 2008). So, several broad-band SVIs such as NDVI, RVI, GNDVI, etc. were used to estimate the LNC. The NDVI as the most widely used SVI performed well in estimating LNC, the possible reason may be that this successful index utilizes the normalized ratio between the reflected energy in the red chlorophyll absorption region and NIR, thus, the difference of these two wavebands can be maximized. In addition, our experiment was conducted in the trumpet period and LAI value was relatively lower (1 to 3 ), which avoid the well-known "saturation" problem. Fig $2 \mathrm{C}$ provides the relationship between GNDVI and LNC, however, it can't obtain the satisfactory result as well as NDVI, the main reason is that the spectrum of chlorophyll reflecting region was substituted by the $569 \mathrm{~nm}$, which means that this index suffered a lot from the bandwidth. In comparison, also, the performance of red edge-based spectral vegetation indices has been evaluated. Fig 3 shows experimental LNC dataset of the field campaign plotted against the values of the selected indices. Overall poorer correlations than the broad-band vegetation indices were obtained but three indices showed a slightly better linear relationship with LNC, being NDRE, REP and TCARI/OSAVI. These indices rely on potions at 550, 670 and around the rededge region $(720,750 \mathrm{~nm})$, although they remain to be evaluated whether these were the most optimized bands in other growth periods. The result indicated that broad-band SVIs were superior to estimate the LNC by using CASI data. A possible reason for this is that spectral resolution of red edgebased SVIs was almost $1 \mathrm{~nm}$ while broad-band SVIs used the central wavelength of the sensors. In addition, the scale effect should also be taken into account. This suggests that it would be worthwhile to simulate the CASI sensor by using the hyperspectral reflectance. Since agriculture decisions are routinely made by the farmers, a simple, robust and up-to-date monitoring application would be most welcome. Specifically, frequent availability of LNC maps will allow the farmer to better monitor the growth of crops and guide to apply fertilizer more accurately. Fig 4 and Fig 5 proposed NDSI proved to be successful in establishing a linear relationship with LNC. The two optimized wavebands were located around the relative chlorophyll absorption and reflection maximum, which is the reason why the estimation accuracy $\left(\mathrm{R}^{2}\right)$ improve to 0.65 . Fig 6 shows that the equation (1) applied to high spatial resolution imagery allows identification of within-field variations in LNC. Overall the higher LNC distribution was located in the northwest and south regions, thus, more fertilizer should be supplied to the other areas.

\section{CONCLUSIONS}

The result of a comparison of the sensitivity of several broadband red edge-based SVIs to LNC from the analysis of several synchronized datasets confirms that the broad-band NDVI performed similarly and constantly better than the selected red edge-based SVIs. In addition to existing indices, in this work, all the bands were optimized using band optimum algorithms. Based on LNC field measurement and CASI hyperspectral data simultaneously collected on July 7, 2012, we have fully exploited the hyperspectral information available in the CASI image. The predictive power of all available two-band combinations has been analyzed according to NDSI and RSI. The wavebands of NDSI that led to best correlation with the LNC dataset were encountered at 626.20 and $569.00 \mathrm{~nm}$, which are sensitive to the physiological status of the plant. It led to an $\mathrm{R}^{2}$ of 0.65 and then subsequently compared against broad-band and red edge-based spectral vegetation indices, which significantly improved the LNC predictive power. Finally, the regression equation between NDSI and LNC was applied to the CASI image for LNC mapping and the result showed that more fertilizer should be supplied to the middle of study areas. This methodology allows identification of within-field variations in LNC, which makes the approach potentially applicable to precision farming when applied to high spatial resolution imagery.

\section{ACKNOWLEDGEMENTS}

This study was supported by the Beijing Natural Science Foundation (4141001), the Natural Science Foundation of China (41271345), the Special Funds for Technology 
innovation capacity building sponsored by the Beijing Academy of Agriculture and Forestry Sciences (KJCX20140417) and the Open Funds of State Key Laboratory of Remote Sensing Science, jointly sponsored by the Institute of Remote Sensing Applications of Chinese Academy of Sciences and Beijing Normal University (OFSLRSS201308).

\section{REFERENCES}

Chen, P., Haboudane, D., Tremblay, N., Wang, J., Vigneault, P., Li, B., 2010. New spectral indicator assessing the efficiency of crop nitrogen treatment in corn and wheat. Remote Sensing of Environment, 114 (9), pp. 1987-1997.

Clevers, Jan G. P. W., Kooistra, L., 2012. Using Hyperspectral Remote Sensing Data for Retrieving Canopy Chlorophyll and Nitrogen Content. IEEE Journal of Selected Topics in Applied Earth Observations and Remote Sensing, 5 (2), pp. 574-583.

Darvishzadeh, R., Matkan, A.A., Dashti Ahangar, A., 2012. Inversion of a Radiative Transfer Model for Estimation of Rice Canopy Chlorophyll Content Using a Lookup-Table Approach. IEEE Journal of Selected Topics in Applied Earth Observations and Remote Sensing, 5 (4), pp. 1222-1230.

Dash, J., Curran, P.J., 2004. The MERIS terrestrial chlorophyll index. International Journal of Remote Sensing, 25 (23), pp. 5403-5413.

Daughtry, C., 2000. Estimating Corn Leaf Chlorophyll Concentration from Leaf and Canopy Reflectance. Remote Sensing of Environment, 74 (2), pp. 229-239.

Feng, W., Guo, B.-B., Wang, Z.-J., He, L., Song, X., Wang, Y.-H., Guo, T.-C., 2014. Measuring leaf nitrogen concentration in winter wheat using double-peak spectral reflection remote sensing data. Field Crops Research, 159, pp. 43-52.

Fitzgerald, G., Rodriguez, D., O’Leary, G., 2010. Measuring and predicting canopy nitrogen nutrition in wheat using a spectral index-The canopy chlorophyll content index (CCCI). Field Crops Research, 116 (3), pp. 318-324.

Gitelson, A.A., 2005. Remote estimation of canopy chlorophyll content in crops. Geophysical Research Letters, 32 (8).

Gitelson, A.A., Merzlyak, M.N., 1996. Signature Analysis of Leaf Reflectance Spectra. Algorithm Development for Remote Sensing of Chlorophyll. Journal of Plant Physiology, 148 (3-4), pp. 494-500.

Guyot G, Baret F, Major D J, 1988. High spectral resolution: determination of spectral shifts between the red and near infrared. International Archives of the Photogrammetry and Remote Sensing. International Archives of the Photogrammetry and Remote Sensing.

Haboudane, D., Miller, J.R., Tremblay, N., Zarco-Tejada, P.J., Dextraze, L., 2002. Integrated narrow-band vegetation indices for prediction of crop chlorophyll content for application to precision agriculture. Remote Sensing of Environment, 81 (23), pp. 416-426.

Heege, H.J., Reusch, S., Thiessen, E., 2008. Prospects and results for optical systems for site-specific on-the-go control of nitrogen-top-dressing in Germany. Precision Agriculture, 9 (3), pp. 115-131.

Inoue, Y., Dabrowska-Zierinska, K., Qi, J., 2012. Synoptic assessment of environmental impact of agricultural management. A case study on nitrogen fertiliser impact on groundwater quality, using a fine-scale geoinformation system. International Journal of Environmental Studies, 69 (3), pp. 443-460.

Kanke, Y., Raun, W., Solie, J., Stone, M., Taylor, R., 2012. RED EDGE AS A POTENTIAL INDEX FOR DETECTING DIFFERENCES IN PLANT NITROGEN STATUS IN WINTER WHEAT. Journal of Plant Nutrition, 35 (10), pp. 1526-1541.

Li, F., Miao, Y., Feng, G., Yuan, F., Yue, S., Gao, X., Liu, Y., Liu, B., Ustin, S.L., Chen, X., 2014a. Improving estimation of summer maize nitrogen status with red edge-based spectral vegetation indices. Field Crops Research, 157, pp. 111-123.

Li, F., Mistele, B., Hu, Y., Chen, X., Schmidhalter, U., 2014b. Reflectance estimation of canopy nitrogen content in winter wheat using optimised hyperspectral spectral indices and partial least squares regression. European Journal of Agronomy, 52, pp. 198-209.

Stroppiana, D., Boschetti, M., Brivio, P.A., Bocchi, S., 2009. Plant nitrogen concentration in paddy rice from field canopy hyperspectral radiometry. Field Crops Research, 111 (1), pp. 119-129.

Tucker, C.J., 1979. Red and photographic infrared linear combinations for monitoring vegetation. Remote Sensing of Environment, 8 (2), pp. 127-150.

Vincini, M., Frazzi, E., D’Alessio, P., 2008. A broad-band leaf chlorophyll vegetation index at the canopy scale. Precision Agriculture, 9 (5), pp. 303-319. 